\title{
Myocardial Infarction with non-obstructed coronaries - atypical presentation of pheochromocytoma
}

\author{
Eka Melson ${ }^{1,2}$, Sidra Amir ${ }^{2}$, Lisa Shepherd ${ }^{1,2}$, Samina Kauser2, Bethan Freestone ${ }^{2}$ and \\ Punith Kempegowda 2
}

IInstitute of Metabolism and Systems Research, University of Birmingham, Birmingham, UK and 2University Hospitals Birmingham NHS Foundation Trust, Birmingham, UK
Correspondence should be addressed to P Kempegowda

Email

p.kempegowda@nhs.net

\section{Summary}

Although pheochromocytoma classically presents with headaches, palpitations and paroxysmal hypertension, atypical presentations such as cardiomyopathy, stroke and subarachnoid haemorrhage have been infrequently documented. We present in this case report, an uncommon presentation of pheochromocytoma with myocardial infarction with normal coronary arteries (MINOCA). A 79-year-old woman presented with central crushing chest pain radiating to left arm associated with headache, palpitations, sweating and difficulty in breathing. For 2 years, she experienced brief episodes of headache, tinnitus, dizziness, palpitations, and sweating that spontaneously resolved. Clinical examination was unremarkable except for high blood pressure $(210 / 105 \mathrm{mmHg})$. Her electrocardiogram showed T wave inversions from V1 to V6 and elevated troponins ( $774 \mathrm{ng} / \mathrm{L}$ at baseline and $932 \mathrm{ng} / \mathrm{L} 3 \mathrm{~h}$ from baseline (normal $<16 \mathrm{ng} / \mathrm{L}$ ) in keeping with a diagnosis of non-ST elevated myocardial infarction. Coronary angiography showed normal coronary arteries. Patient was hence treated as myocardial infarction with normal coronaries (MINOCA). Despite appropriate treatment for MINOCA, she continued to experience episodic headaches, palpitations, dizziness and erratic blood pressures (particularly severe hypertension shortly after beta-blocker administration). Further investigations revealed raised urine noradrenaline of $4724 \mathrm{nmol} / 24 \mathrm{~h}(<554 \mathrm{nmol} / 24 \mathrm{~h}$ ) and urine adrenaline of $92863 \mathrm{nmol} / 24 \mathrm{~h}(<77 \mathrm{nmol} / 24 \mathrm{~h})$. Computerised tomography demonstrated a well-defined rounded mass in right adrenal gland morphological of pheochromocytoma. She underwent laparoscopic right adrenalectomy with histology confirming pheochromocytoma. This case highlights the importance of thorough investigation for the underlying cause for MINOCA. In patients with unexplained erratic blood pressure control, pheochromocytoma should be considered as a differential diagnosis.

\section{Learning points:}

- Pheochromocytoma is rare tumour that often presents with non-specific symptoms.

- It is important to investigate underlying cause of MINOCA.

- Thorough history is the key to diagnosis.

\section{Background}

Pheochromocytoma is a rare neuroendocrine tumour of the adrenal medulla classically presenting with episodic headaches, diaphoresis, palpitations and paroxysmal hypertension. The non-specific, episodic and heterogeneity in its clinical presentation often lead to years of delayed diagnosis (1). Blood and urinary catecholamines and metanephrines can be helpful to aid its diagnosis followed by computed tomography (CT) scan 
of the adrenal gland to localise the tumour. Other imaging studies such as magnetic resonance imaging (MRI), scintigraphy and positron emission tomography (PET) scan could all be used if CT is inappropriate/not available or in the event when CT is negative despite convincing biochemical profile. Furthermore, it is important to note that imaging should be done only when there is biochemical confirmation of pheochromocytoma (2).

These tumours release rapid and massive amount of catecholamines that can cause life-threatening cardioand cerebrovascular complications (3). Data in 2012 showed $19.3 \%$ subjects with pheochromocytoma had a relatively high incidence of cardiovascular complications. These complications include cardiac arrhythmia, ST and non-ST elevation MI, heart failure, hypertensive urgency, TIA, stroke, and subarachnoid haemorrhage (4).

In our case report, we present a case of pheochromocytoma presenting with myocardial infarction with non-obstructed coronary arteries (MINOCA). The diagnosis of MINOCA requires (i) the diagnosis of myocardial infarction; (ii) evidence of non-obstructive coronary arteries on angiography; (iii) no clinically overt specific cause for the acute presentation (5).

We highlight in this case report the importance of identifying and investigating for an underlying cause of MINOCA, to avoid life-threatening complications such as the cardio and cerebrovascular complications of pheochromocytoma.

\section{Case presentation}

A 79-year-old Caucasian woman presented to the emergency department with crushing retrosternal chest pain radiating to her left arm. The pain woke her up from sleep in the early hours of the morning, and associated with shortness of breath, palpitations, sweating, nausea and headache. She was previously diagnosed with hypertension and tinnitus and was taking bendroflumethiazide and propranolol. There was no significant family history of note. She was otherwise fit and well, did not smoke or drink alcohol.

On examination, cardiovascular and respiratory examinations were unremarkable, although her blood pressure was noted to be $210 / 105 \mathrm{mmHg}$. Serial electrocardiogram (ECG) showed normal sinus rhythm, mild ST elevation in leads I, AVL, V5-6 and T wave inversion across V1-6 (Fig. 1). Blood tests were normal except high-sensitivity troponins of $774 \mathrm{ng} / \mathrm{L}$ and $932 \mathrm{ng} / \mathrm{L}$ (normal $<16 \mathrm{ng} / \mathrm{L}$ ). Following evaluation, she was diagnosed with acute coronary syndrome (ACS) and treated as per local hospital guidelines. Interestingly, her coronary angiogram showed non-obstructed coronary arteries. Hence, her diagnosis was revised to MINOCA.

\section{Investigation}

During her hospital stay, patient's blood pressure showed erratic fluctuations from $210 / 100$ to $94 / 74 \mathrm{mmHg}$ (Fig. 2) associated with symptoms mentioned previously. During one episode she became acutely hypotensive (systolic $<60 \mathrm{mmHg}$, unreportable diastolic) and required management with intravenous fluids. On further enquiry, patient reported symptoms spontaneously resolving after a few minutes. Symptoms were evident 2 years ago with increasing frequency in the past 4 months, resulting in multiple visits to the emergency department. These episodic symptoms and erratic blood pressure pattern raised the suspicion of pheochromocytoma. Investigations revealed raised urinary catecholamines. These biochemical tests were all elevated and summarised in Table 1. Plasma normetadrenaline and adrenaline were
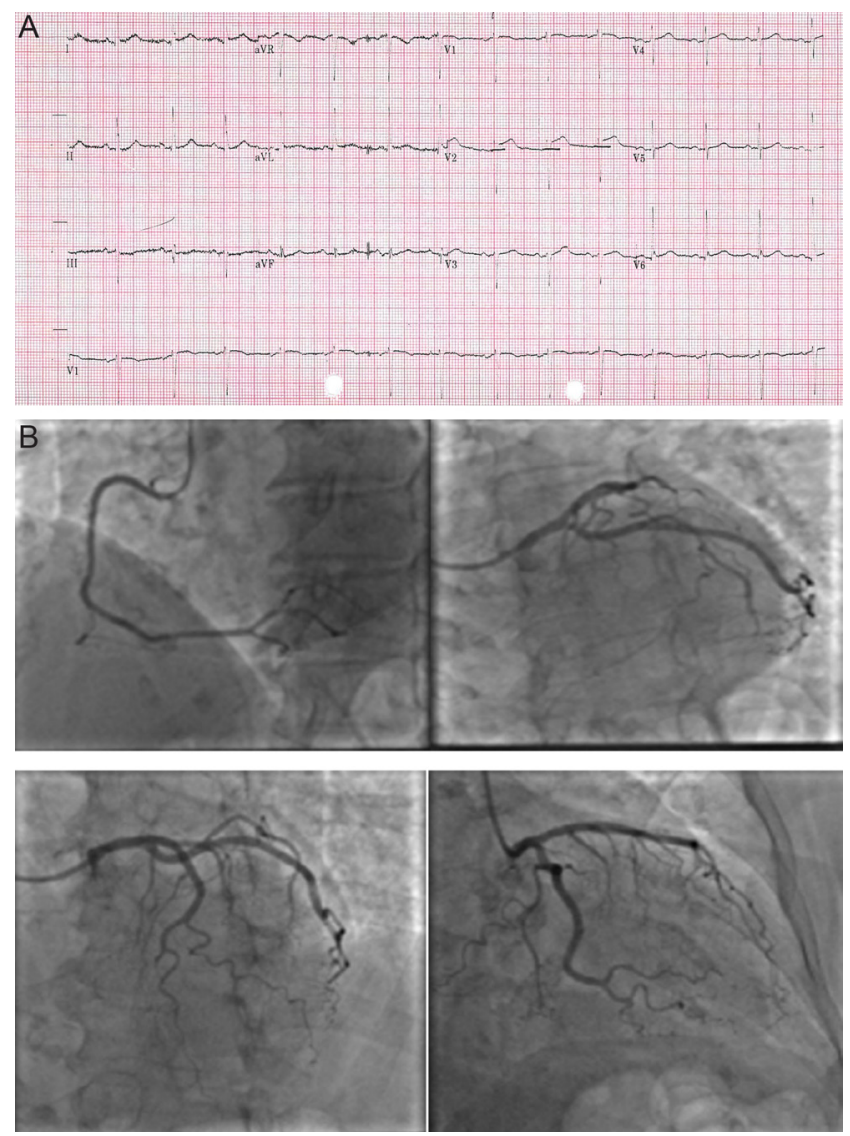

Figure 1

ECG showing non-ST elevation myocardial Infarction (A) and coronary angiogram showing non-obstructed coronaries (B). 


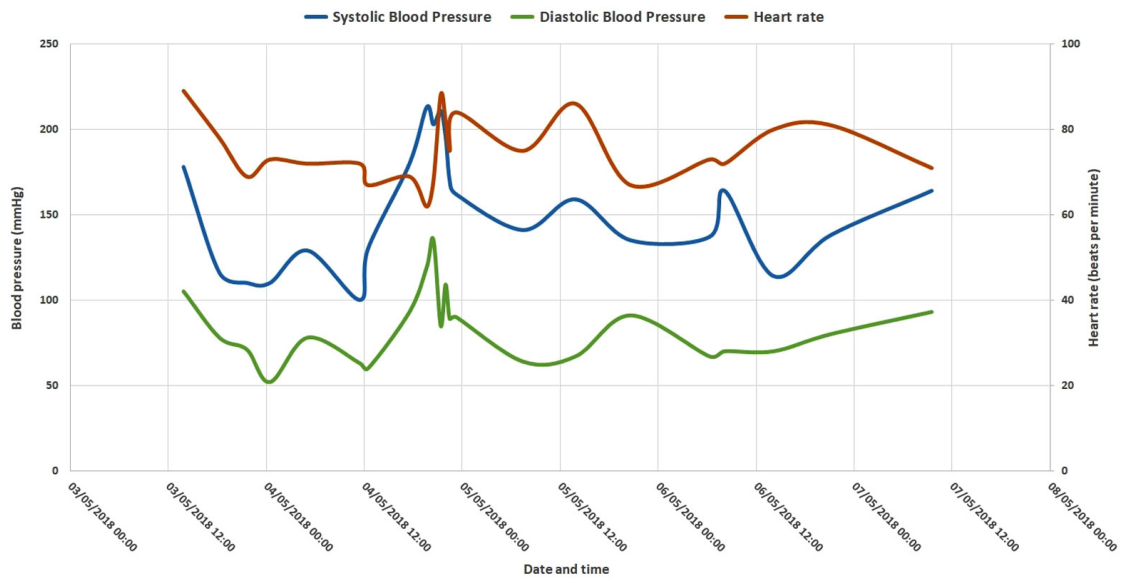

\section{Figure 2}

Patient's observations during her inpatient stay demonstrating labile blood pressure, a sign of pheochromocytoma. also elevated at $1980 \mathrm{pmol} / \mathrm{L}$ (reference $<1180 \mathrm{pmol} / \mathrm{L}$ ) and $1288 \mathrm{pmol} / \mathrm{L}$ (reference $<510 \mathrm{pmol} / \mathrm{L}$ ) respectively. Computerised tomography scan showed well-defined rounded mass in right adrenal gland, measuring $5 \mathrm{~cm} \times 3.7 \mathrm{~cm} \times 5 \mathrm{~cm}$. 123I MIBG SPECT scan showed increased uptake in the right adrenal gland in line with a diagnosis of pheochromocytoma but did not show any metastatic activity (Fig. 3).

\section{Treatment}

Patient was diagnosed with pheochromocytoma and medically stabilised with alpha- and beta-adrenergic receptor blocker (doxazocin and bisoprolol). She underwent laparoscopic right adrenalectomy following consensus by the adrenal multiple disciplinary team.

\section{Outcome and follow-up}

Surgical and post-operative care was uncomplicated. Post-operative histology revealed a completely excised pheochromocytoma, with a Pheochromocytoma of the Adrenal gland Scaled Score (PASS) of 4, Ki-67 of $<1 \%$ and normally expressed SDHA and SDHB genes. Follow-up bloods 6 weeks post surgery revealed plasma normetadrenaline of $1084 \mathrm{pmol} / \mathrm{L}(<1180)$, metadrenaline of $<100(<510)$ and 3-methoxythyramine of $<100 \mathrm{pmol} / \mathrm{L}$ $(<180)$. She was then referred to the genetic team to exclude a genetic cause of pheochromocytoma and is due to be followed up in the endocrine clinic in 6 months.

\section{Discussion}

As our case demonstrates it is important for the caring physician to further investigate the underlying aetiology of MIOCA. Differential diagnoses for MINOCA include plaque disruption, coronary artery spasm, thromboembolism, coronary dissection, takotsubo cardiomyopathy, unrecognised myocarditis and other forms of type-2 myocardial infarction (5).

Type-2 MI is an umbrella term used to describe myocardial cell necrosis secondary to supply-demand

Table 1 Pre-operative values of catecholamines biochemically confirmed pheochromocytoma. Post-operative values confirm biochemical resolution of pheochromocytoma.

\begin{tabular}{|c|c|c|c|}
\hline \multirow[b]{2}{*}{ Catecholamines } & \multicolumn{2}{|c|}{ Pre-op } & \multirow[b]{2}{*}{ Post-op } \\
\hline & Sample 1 & Sample 2 & \\
\hline Urine noradrenaline & $4724 \mathrm{nmol} / 24 \mathrm{~h}$ & $1090 \mathrm{nmol} / 24 \mathrm{~h}$ & \\
\hline Urine adrenaline & $2863 \mathrm{nmol} / 24 \mathrm{~h}$ & $233 \mathrm{nmol} / 24 \mathrm{~h}$ & \\
\hline Urine normetadrenaline & $17.90 \mu \mathrm{mol} / 24 \mathrm{~h}$ & $7.52 \mu \mathrm{mol} / 24 \mathrm{~h}$ & \\
\hline Urine metadrenaline & $20.00 \mu \mathrm{mol} / 24 \mathrm{~h}$ & $7.97 \mu \mathrm{mol} / 24 \mathrm{~h}$ & \\
\hline Plasma normetadrenaline & & 1980 pmol/L & 1084 \\
\hline Plasma metadrenaline & & $1288 \mathrm{pmol} / \mathrm{L}$ & $<100$ \\
\hline Plasma 3-methoxytyramine & & $<100$ & $<100$ \\
\hline Plasma renin & & $24.7 \mathrm{mu} / \mathrm{L}$ & \\
\hline Aldosterone & & $189 \mathrm{pmol} / \mathrm{L}$ & \\
\hline Renin/aldosterone ratio & & 8 & \\
\hline DHEA sulphate & & $1.28 \mu \mathrm{mol} / \mathrm{L}$ & \\
\hline
\end{tabular}

\begin{tabular}{c}
\hline Reference range \\
\hline$<554 \mathrm{nmol} / 24 \mathrm{~h}$ \\
$<77 \mathrm{nmol} / 24 \mathrm{~h}$ \\
$<4.90 \mu \mathrm{mol} / 24 \mathrm{~h}$ \\
$<2.0 \mu \mathrm{mol} / \mathrm{h}$ \\
$<1180 \mathrm{pmol} / \mathrm{L}$ \\
$<510 \mathrm{pmol} / \mathrm{L}$ \\
$<180 \mathrm{pmol} / \mathrm{L}$ \\
Ambulatory: $6.1-62.7 \mathrm{mu} / \mathrm{L} ;$ \\
Supine: $4.2-59.7 \mathrm{mu} / \mathrm{L}$ \\
$<750 \mathrm{pmol} / \mathrm{L}$ \\
$<91$ \\
$0.33-4.18 \mu \mathrm{mol} / \mathrm{l}$
\end{tabular}




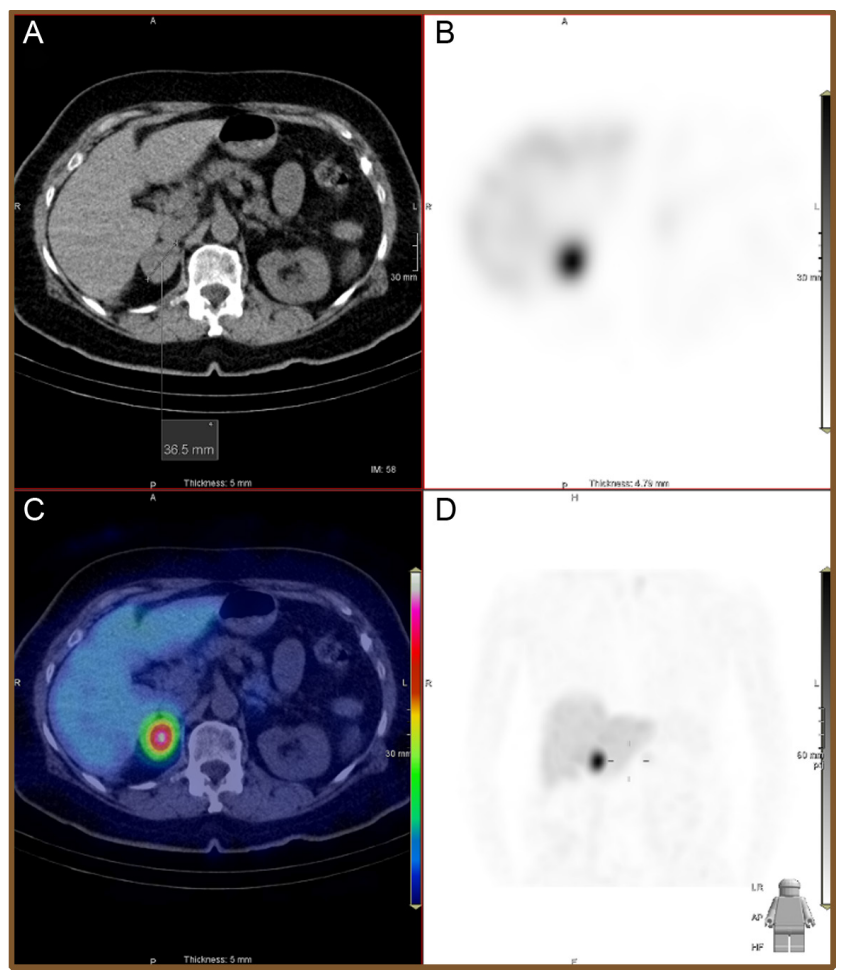

Figure 3

SPECT CT showing a $37 \mathrm{~mm}$ maximum axial diameter soft tissue density mass lesion seen in the right adrenal (A) with abnormal increased accumulation of MIBG (C). No other abnormal accumulation of activity is seen elsewhere to indicate the presence of metastatic disease on the planar (B and D) or the SPECT CT images.

mismatch including an increased oxygen demand caused by sudden excessive secretion of catecholamines by pheochromocytoma (6).

This case illustrates the importance of taking a detailed history, including patient reported symptoms, at each contact with a healthcare professional. Investigation of non-specific intermittent symptoms prior to the index admission, may have led to the diagnosis of pheochromocytoma and prevention of the subsequent complication of MINOCA.

Potentially there are two points that may aid the diagnosis and subsequent management of this patient population. Whilst there is a clear diagnostic criteria and investigation pathway for MINOCA, provided by the European Society of Cardiology guidelines, it is noted that investigation for pheochromocytoma is not included nor as one of the differential diagnoses for MINOCA (5). The former may be due to the low incidence and prevalence of pheochromocytoma making screening invaluable in terms of cost and benefits (1). A diagnostic pathway to include pheochromocytoma as a differential diagnosis for MINOCA is needed as appropriate management of the pheochromocytoma has been shown to significantly improve the myocardial changes seen in MINOCA. This is especially important in patients with unexplained erratic blood pressure and symptoms suggestive of pheochromocytoma. Early diagnosis of pheochromocytoma is also essential as medical management used in other conditions (e.g. myocardial infarction) might be contraindicated in pheochromocytoma worsening its prognosis (6).

Secondly, there is no specific management guideline for patients with pheochromocytoma presenting with MINOCA. As with other patients with pheochromocytoma, our patient was managed with adequate alpha- and betareceptor blockage followed by laparoscopic adrenalectomy (7). PASS score, derived from the tumour's pathological features after surgery, has been used to separate tumours that behave in a benign way $(\mathrm{PASS}<4$ ) with more aggressive tumours (PASS $>4$ ). Interestingly, her PASS score of 4 indicated that it was an aggressive tumour which may have contributed to the unusual clinical presentation of our patient (8). Her Ki-67 score of $<1 \%$ is reassuring for the benign nature of the tumour (9). However, there is no evidence correlating PASS score and clinical presentation of the disease. Our patient was also referred for genetic screening, as approximately $35 \%$ of pheochromocytoma are a manifestation of a hereditary syndrome, such as multiple endocrine neoplasia type 2 or Von HippelLindau syndrome (10).

In conclusion, we highlight the importance of thorough history taking and investigation for the underlying aetiology of MINOCA. In patients with unexplained erratic blood pressure control, pheochromocytoma should be considered as a differential diagnosis.

\section{Patient's perspective}

Our patient was frustrated due to the delayed diagnosis, as her family believed that she presented with classic symptoms suggestive of pheochromocytoma. However, she is relieved that she is cured from the pheochromocytoma with reassuring follow-up results.

\section{Declaration of interest}

The authors declare that there is no conflict of interest that could be perceived as prejudicing the impartiality of the research reported.

\section{Funding}

This research did not receive any specific grant from any funding agency in the public, commercial or not-for-profit sector. 


\section{Patient consent}

Written informed consent for publication of their clinical details and/or clinical images was obtained from the patient.

\section{Author contribution statement}

$E M$ and $S A$ were involved in case management, arranging investigations and writing the first draft of the case report. LS and S K carried out all endocrine investigations and arranged appropriate follow-up. B F was the admitting consultant who carried out coronary angiogram and diagnosed MINOCA and investigated for pheochromcytoma. P K supervised the endocrine investigations of the patient, diagnosed pheochromocytoma and referred to MDT for consideration for surgery. All authors have equally contributed with constructive criticism to the final version of the case report.

\section{References}

1 DeLellis RA, Lloyd RV \& Heitz PU, Eds. World Health Organization classification of tumours. In Pathology and Genetics of Tumour of Endocrine Organs, pp. 147-156. Lyon: IARC Press, 2004.

2 Stein P \& Black H A simplified diagnostic approach to pheochromocytoma. A review of the literature and report of one institution's experience. Medicine 199170 46-66. (https://doi. org/10.1097/00005792-199101000-00004)

3 Imam T, Finny P, Choo-Kang A \& Khan R Phaeochromocytoma presenting as an acute coronary syndrome. BMJ Case Reports 2016 2016 bcr2016214737. (https://doi.org/10.1136/bcr-2016-214737)

4 der Menke-van Houven van Oordt CW, Twickler hB, van Asperdt FGMH, Ackermans P \& Hermus ARRM Pheochromocytoma mimicking an acute myocardial infarction. Netherlands Heart Journal 200715 248-251. (https://doi.org/10.1007/BF03085991)

5 Agewall S, Beltrame JF, Reynolds HR, Niessner AG, Rosano G, Caforio ALP, De Caterina R, Zimarino M, Roffi M, Kjeldsen K, et al. ESC working group position paper on myocardial infarction with non-obstructive coronary arteries. European Heart Journal 201638 ehw149. (https://doi.org/10.1093/eurheartj/ehw149)

6 Niccoli G, Scalone G \& Crea F Acute myocardial infarction with no obstructive coronary atherosclerosis: mechanisms and management. European Heart Journal 201536 475-481. (https://doi.org/10.1093/ eurheartj/ehu469)

7 Lenders JW, Duh QY, Eisenhofer G-RA, Gimenez-Roqueplo AP, Grebe SK, Murad MH, Naruse M, Pacak K, Young WF \& Endocrine Society Pheochromocytoma and paraganglioma: an Endocrine Society clinical practice guideline. The Journal of Clinical Endocrinology \& Metabolism 201499 1915-1942. (https://doi.org/10.1210/jc.20141498)

8 Thompson LD Pheochromocytoma of the Adrenal gland Scaled Score (PASS) to separate benign from malignant neoplasms: a clinicopathologic and immunophenotypic study of 100 cases. The American Journal of Surgical Pathology 200226 551-566. (https://doi. org/10.1097/00000478-200205000-00002)

9 Rakowski T, De Luca G, Siudak Z, Plens KA, Dziewierz A, Kleczyński P, Tokarek T, Węgiel M, Sadowski M \& Dudek D Characteristics of patients presenting with myocardial infarction with non-obstructive coronary arteries (MINOCA) in Poland: data from the ORPKI national registry. Journal of Thrombosis and Thrombolysis 201947 462-466. (https://doi.org/10.1007/s11239-018-1794-z)

10 Martins R \& Bugalho MJ Paragangliomas/pheochromocytomas: clinically oriented genetic testing. International Journal of Endocrinology 20142014 794187. (https://doi. org/10.1155/2014/794187)

Received in final form 26 September 2019 Accepted 01 October 2019 